\title{
Organic-Inorganic Hybrid Liquid Crystals: Thermotropic Mesophases Formed by Hybridization of Liquid-Crystalline Phosphates and Monodispersed $\alpha-\mathrm{Fe}_{2} \mathrm{O}_{3}$ Particles
}

\author{
Kiyoshi Kanie* and Atsushi Muramatsu* \\ Institute of Multidisciplinary Research for Advanced Materials, Tohoku University \\ Katahira 2-1-1, Aoba-ku, Sendai 980-8577, Japan
}

\section{Supporting Information}

\section{General}

All reagents of the highest commercial quality and solvents (Aldrich Chemicals, Wako Pure Chemicals, Nakalai Tesque, Kanto Chemicals, or Tokyo Kasei) were used as received. Water was doubly distilled and deionized prior to use. All of the organic reactions were carried out under an argon atmosphere in a dry solvent. Glass vessels for the organic reactions were well-dried by heating under reduced pressure. Completion of the reactions was monitored by thin-layer chromatography using $0.25 \mathrm{~mm}$ E. Merck silica-gel plates (Silica Gel F254) with a visualizing device of UV light and/or by dipping the plates in an ethanolic sodium phosphomolybdate followed by heating. Silica gel from Kanto Chemicals (Silica Gel 60, Spherical, 40-100 $\mu \mathrm{m}$ ) was used for flash column chromatography. Recycling preparative GPC was carried out using a Japan Analytical Industry LC-9201 chromatograph.

Measurements of phase transition temperatures and determinations of liquid-crystalline phases were carried out with an Olympus BX51 optical polarizing microscope equipped with a Mettler FP82 HT hot stage. Thermal characterization was performed with a TA Instruments MDSC Q-100 equipped with a liquid nitrogen cooling system. The scanning rate was $10{ }^{\circ} \mathrm{C} / \mathrm{min}$. Infrared (IR) spectra were conducted on a Bio-Rad FTS-7000 equipped with a microscope UMA-600. IR measurements for 
characterization of molecules were carried out by using an ATR unit. Variable-temperature IR spectra were recorded on the microscope UMA-600 equipped with a hot stage. Samples were sandwiched with a couple of $\mathrm{KBr}$ plate-like crystals for the measurements. NMR spectra were measured in a $\mathrm{CDCl}_{3}$ solution unless otherwise noted. ${ }^{1} \mathrm{H}$ and ${ }^{13} \mathrm{C}$ NMR spectra were recorded on a JEOL JNM-LA400 at $400\left({ }^{1} \mathrm{H}\right)$ and $100.7\left({ }^{13} \mathrm{C}\right) \mathrm{MHz}$. Chemical shifts of ${ }^{1} \mathrm{H}$ NMR signals were quoted to internal standard $\mathrm{Me}_{4} \mathrm{Si}(\delta=0.00)$ and expressed as chemical shifts in ppm $(\delta)$, multiplicity, coupling constant $(\mathrm{Hz})$, and relative intensity. Chemical shifts of ${ }^{13} \mathrm{C}$ NMR signals were quoted to internal standard $\mathrm{CDCl}_{3}(\delta=77.0)$ or dimethyl sulfoxide- $d_{6}(\delta=40.96)$ and listed as chemical shifts in ppm $(\delta) .{ }^{31} \mathrm{P}$ NMR spectra were recorded on a Bruker AVANCE-600 at $242.9 \mathrm{MHz}$, and the chemical shifts were quoted to external standard using aqueous $85 \% \mathrm{H}_{3} \mathrm{PO}_{4}(\delta=0.00)$ and expressed as chemical shifts in ppm $(\delta)$. X-ray photoelectron spectroscopic (XPS) measurements were carried out by a PHI 5600 ESCA system using $\mathrm{Al} \mathrm{K} \alpha$ radiation. Electron impact mass spectra were taken on a Hitachi M-2500S spectrometer $(70 \mathrm{eV})$. High resolution mass spectra (HRMS) were recorded on a Bruker FT-MS APEXIII spectrometer by using electron spray ionization (ESI) mode. Elemental analyses were carried out by Elemental Analysis Laboratory, Institute of Multidisciplinary Research for Advanced Materials, Tohoku University, using a Yanako MT-6 CHN Corder. Wide angle X-ray diffraction (WAXD) measurements of $\alpha-\mathrm{Fe}_{2} \mathrm{O}_{3}$ particles were carried out on a Rigaku RAD-B system using Ni-filtered $\mathrm{CuK} \alpha$ radiation $(40 \mathrm{kV}, 20 \mathrm{~mA})$. Variable-temperature WAXD profiles were recorded on a Rigaku RINT-H system with a heating stage using a CuK $\alpha$ beam $(40 \mathrm{kV}, 40 \mathrm{~mA})$. Temperature variable small angle X-ray scattering (SAXS) measurements were carried out by using a Rigaku Nano-viewer system equipped with a Mettler FP82 HT hot stage. Rheological measurements were performed on a TA Instruments ARES system. Transition electron microscopic (TEM) observations were performed by using a JEM-1200EX II with an acceleration voltage of $120 \mathrm{kV}$. Surface area measurements of $\alpha-\mathrm{Fe}_{2} \mathrm{O}_{3}$ particles were performed on a Belsorp-mini by using nitrogen adsorption (BET method). 


\section{Synthesis of Organic Molecules}

\section{2-1. Preparation of 4-\{trans-4-[trans-4-(3,4-Difluorophenyl)cyclohexyl]cyclohexyl\} butyl phosphate (L1)}

Preparation of $\mathbf{L 1}$ was carried out by the route as shown in Scheme S1.
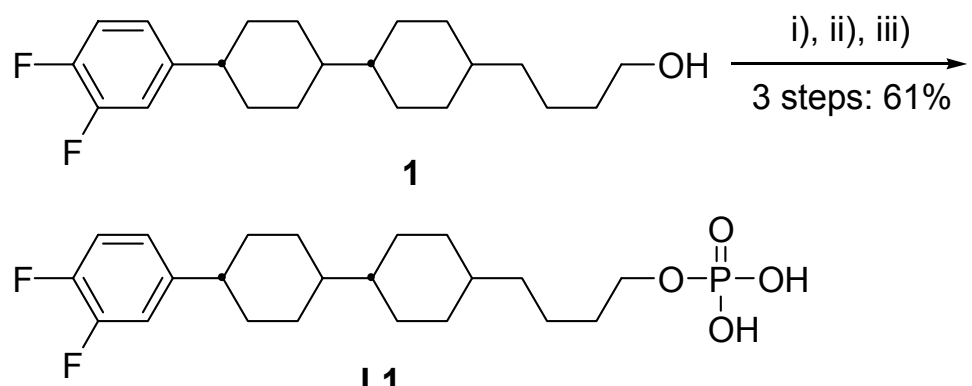

L1

i) $1 \mathrm{H}$-Tetrazole (3.0 mol), Di-tert-butyl diisopropylphosphoramidite $(1.2$ mol), THF, $0{ }^{\circ} \mathrm{C}$ to rt, $3 \mathrm{~h}$; ii) $m$-CPBA (2.0 mol); iii) $\mathrm{CF}_{3} \mathrm{CO}_{2} \mathrm{H} / \mathrm{CH}_{2} \mathrm{Cl}_{2}$ $(1 / 2), 0^{\circ} \mathrm{C}, 30 \mathrm{~min}$.

Scheme S1. Synthesis of Mesogenic Molecule L1.

The procedure is as follows: To a THF $(20 \mathrm{~mL})$ solution of trans-4-[trans-4-(3,4-difluorophenyl)cyclohexyl]cyclohexane butanol (1) ${ }^{\mathrm{S} 1}(1.75 \mathrm{~g}, 5.0$ mmol) and $1 H$-tetrazole (1.05 g, $15 \mathrm{mmol})$, di-tert-butyl diisopropylphosphoramidite $(2.2 \mathrm{~mL}, 7.0 \mathrm{mmol})$ was added dropwise at $0{ }^{\circ} \mathrm{C}$ over $10 \mathrm{~min}$ with stirring under an argon atmosphere. The resulting solution was allowed to warm to room temperature over $30 \mathrm{~min}$, and stirred at the temperature for $3 \mathrm{~h}$. Then, a dichloromethane $(10 \mathrm{~mL})$ solution of $m$-CPBA $(65 \%, 2.65 \mathrm{~g}, 10.0 \mathrm{mmol})$ was added dropwise into the reaction mixture at $0{ }^{\circ} \mathrm{C}$. The resulting solution was allowed to warm to room temperature, stirred for $10 \mathrm{~min}$, and poured into a separation funnel containing $\mathrm{Et}_{2} \mathrm{O}(100 \mathrm{~mL})$, water $(100 \mathrm{~mL})$, and a $10 \% \mathrm{NaHSO}_{3}$ aqueous solution $(20 \mathrm{~mL})$. The organic phase was separated, and the aqueous phase was extracted three times with $\mathrm{Et}_{2} \mathrm{O}$ (total, $200 \mathrm{~mL}$ ). The combined organic extracts were washed with an aqueous $5 \% \mathrm{NaHSO}_{3}$ solution, a sat. aqueous $\mathrm{NH}_{4} \mathrm{Cl}$ solution, an aqueous $\mathrm{NaOH} / \mathrm{NaHCO}_{3}$ solution $(\mathrm{pH}=10)$, and a sat. aqueous $\mathrm{NaCl}$ solution, successively. The resulting extracts were dried over anhydrous $\mathrm{MgSO}_{4}$, filtered through a pad of Celite, and concentrated under reduced pressure. The 
residue was purified by flash column chromatography on Silica gel (eluent: hexane : EtOAc $=3: 1$ to $1: 1$ ) to give $4-\{$ trans-4-[trans-4-(3,4-difluorophenyl)cyclohexyl]cyclohexyl \} butyl di-tert-butyl phosphate (2) in a yield of $64 \%(1.73 \mathrm{~g}, 3.20 \mathrm{mmol})$ as a colorless oil.

To a dichloromethane $(10 \mathrm{~mL})$ solution of $2(1.73 \mathrm{~g}, 3.20 \mathrm{mmol}), 5 \mathrm{ml}$ of trifluoroacetic acid was slowly added dropwise at $0{ }^{\circ} \mathrm{C}$ with stirring. The resulting mixture was stirred at the temperature for $30 \mathrm{~min}$, and concentrated by rotary evaporator at $40{ }^{\circ} \mathrm{C}$ and dried under reduced pressure to obtain the desired product $\mathbf{L 1}$, in a yield of $96 \%(1.32 \mathrm{~g}, 3.07 \mathrm{mmol})$ as white precipitates. Further purification was not necessary.

Compound L1: $\mathrm{C}_{22} \mathrm{H}_{33} \mathrm{~F}_{2} \mathrm{O}_{4} \mathrm{P}$. Phase transition temperature ( $\left.{ }^{\circ} \mathrm{C}\right)$ : G -50 $\mathrm{M}_{1} 77 \mathrm{M}_{2} 129$ $\mathrm{S}_{\mathrm{A}} 193 \mathrm{~N} 194$ Iso (DSC on the second heating). IR (ATR) 2911, 2847, 2660, 2250, 1607, $1519,1450,1275,1211,1175,1020,973,818 \mathrm{~cm}^{-1} ;{ }^{1} \mathrm{H}$ NMR (400 MHz) $\delta=0.81-1.42$ $(\mathrm{m}, 15 \mathrm{H}), 1.63-1.91(\mathrm{~m}, 10 \mathrm{H}), 2.39(\mathrm{tt}, J=3,12 \mathrm{~Hz}, 1 \mathrm{H}), 4.01-4.09(\mathrm{~m}, 2 \mathrm{H})$, 6.85-7.07 (m, $3 \mathrm{H}), 8.61$ (brs, $2 \mathrm{H}) ;{ }^{13} \mathrm{C}$ NMR $(100 \mathrm{MHz}) \delta=22.8(\mathrm{~d}, J=5 \mathrm{~Hz}), 30.0$, $30.1,30.4$ (d, $J=6 \mathrm{~Hz}), 33.5,34.5,37.0,37.8,42.7,43.2,43.8,68.0$ (m), 115.3 (d, $J=$ $17 \mathrm{~Hz}), 116.7$ (d, $J=16 \mathrm{~Hz}), 122.4,(\mathrm{dd}, J=3,3 \mathrm{~Hz}), 144.7$ (dd, $J=4,4 \mathrm{~Hz}), 148.4$ (dd, $J=13,244 \mathrm{~Hz}), 150.1(\mathrm{dd}, J=12,245 \mathrm{~Hz}) ;{ }^{31} \mathrm{P}$ NMR $(242.9 \mathrm{MHz}) \delta=2.14$; MS $m / z$ (rel intensity) $351\left(\mathrm{M}^{+}-\mathrm{HPO}_{3}, 23\right), 350\left(\mathrm{M}^{+}-\mathrm{H}_{2} \mathrm{PO}_{3}, 100\right), 333\left(\mathrm{M}^{+}-\mathrm{H}_{2} \mathrm{PO}_{4}, 13\right), 332$ (54), 304 (3.6), 290 (7.9), 275 (9.3), 195 (15), 193 (15), 179 (27), 140 (62), 127 (89), 95 (80). HRMS calcd for $\left[\mathrm{C}_{22} \mathrm{H}_{33} \mathrm{~F}_{2} \mathrm{O}_{4} \mathrm{P}+\mathrm{Na}\right]^{+}:$453.1977. Found: 453.1976. Elemental anal. calcd for $\mathrm{C}_{22} \mathrm{H}_{33} \mathrm{~F}_{2} \mathrm{O}_{4} \mathrm{P}: \mathrm{C}, 61.38 ; \mathrm{H}, 7.73 \%$. Found: $\mathrm{C}, 61.51 ; \mathrm{H}, 7.94 \%$. 


\section{2-2. Synthesis of 1-trans-Butyl-4-[trans-4-(3,4-difluorophenyl)cyclohexyl]-}

cyclohexane (L2)

Compound L2 was prepared by the hydrogenation of 4-\{trans-4-[trans-4-(3,4-difluorophenyl)cyclohexyl]cyclohexyl\}butene, which was kindly donated from Dainippon Ink \& Chemicals, Inc., as shown in Scheme S2.

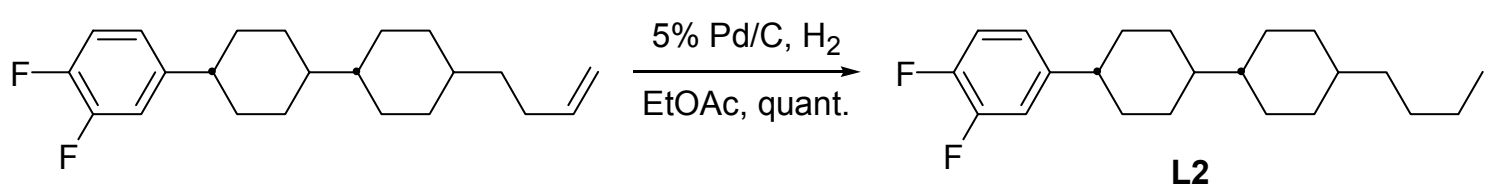

Scheme S2. Synthesis of $\mathbf{L 2}$.

Compound L2: $\mathrm{C}_{22} \mathrm{H}_{32} \mathrm{~F}_{2}$. Phase transition temperature $\left({ }^{\circ} \mathrm{C}\right)$ : $\mathrm{Cr} 41 \mathrm{~S}_{\mathrm{B}} 45 \mathrm{~N} 121$ Iso (DSC on the second heating). IR (ATR) 2911, 2846, 1607, 1519, 1450, 1432, 1285, 1211, 1113, 944, 865, $835 \mathrm{~cm}^{-1} ;{ }^{1} \mathrm{H}$ NMR (400 MHz) $\delta=0.81-1.40(\mathrm{~m}, 16 \mathrm{H}), 0.88(\mathrm{t}, J$ $=7 \mathrm{~Hz}, 3 \mathrm{H}), 1.70-1.95(\mathrm{~m}, 9 \mathrm{H}), 2.40(\mathrm{tt}, J=3,12 \mathrm{~Hz}, 1 \mathrm{H}), 6.68-7.07(\mathrm{~m}, 3 \mathrm{H}) ;{ }^{13} \mathrm{C}$ NMR $(100 \mathrm{MHz}) \delta=14.2,23.0,29.3,30.08,30.16,33.6,34.6,37.2,37.9,42.8,43.3$, 43.9, $115.4(\mathrm{~d}, J=17 \mathrm{~Hz}), 116.7(\mathrm{~d}, J=17 \mathrm{~Hz}), 122.5$, (dd, $J=3,6 \mathrm{~Hz}), 144.9$ (dd, $J=$ 4, $4 \mathrm{~Hz}$ ), 148.4 (dd, $J=12,244 \mathrm{~Hz}), 150.1$ (dd, $J=13,245 \mathrm{~Hz})$; MS $m / z$ (rel intensity) $336\left(\mathrm{M}^{+}+2,2.7\right), 335\left(\mathrm{M}^{+}+1,24\right), 334\left(\mathrm{M}^{+}, 100\right), 196$ (6.2), 153 (7.6), 140 (27), 127 (26). Elemental anal. calcd for $\mathrm{C}_{22} \mathrm{H}_{32} \mathrm{~F}_{2}$ : C, 79.00; H, 9.64\%. Found for: C, 79.06; H, $9.84 \%$. 


\section{2-3. Preparation of 6-(4'-Cyano-biphenyl-4-yloxy)hexyl Phosphate (L3)}

Synthesis of $\mathbf{L 3}$ was carried out by the same way for the preparation of $\mathbf{L 1}$ starting from 4-cyano-4'-hydroxybiphenyl. The synthetic route is shown in Scheme S3.

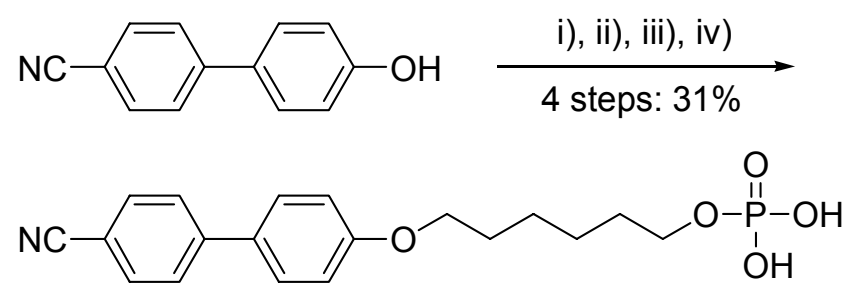

L3

i) 6-Bromohexanol (1.1 mol), $\mathrm{K}_{2} \mathrm{CO}_{3}(2.0 \mathrm{~mol}), \mathrm{DMF}, 100{ }^{\circ} \mathrm{C}, 4 \mathrm{~h}$;

ii) $1 \mathrm{H}$-Tetrazole (2.0 mol), Di-tert-butyl diisopropylphosphoramidite

(1.2 mol), THF, $0{ }^{\circ} \mathrm{C}$ to rt, $2 \mathrm{~h}$; iii) $\mathrm{H}_{2} \mathrm{O}_{2}(2.6 \mathrm{~mol}), \mathrm{Et}_{3} \mathrm{~N}(9.0 \mathrm{~mol})$;

iv) $\mathrm{CF}_{3} \mathrm{CO}_{2} \mathrm{H} / \mathrm{CH}_{2} \mathrm{Cl}_{2}(1 / 2), 0{ }^{\circ} \mathrm{C}, 30 \mathrm{~min}$.

Scheme S3. A Synthetic Route for the Preparation of $\mathbf{L 3 .}$

Compound L3: $\mathrm{C}_{19} \mathrm{H}_{22} \mathrm{NO}_{5} \mathrm{P}$. Phase transition temperature $\left({ }^{\circ} \mathrm{C}\right): \mathrm{G}-4 \mathrm{M} 57 \mathrm{~S}_{\mathrm{A}} 146$ Iso (DSC on the second heating). IR (ATR) 2941, 2868, 2750, 2250, 2235, 1603, 1519, 1494, 1472, 1397, 1288, 1252, 1116, 1008, 969, $820 \mathrm{~cm}^{-1} ;{ }^{1} \mathrm{H}$ NMR (400 MHz, $\left.\mathrm{DMSO}_{-} \mathrm{d}_{6}\right) \delta=1.34-1.49(\mathrm{~m}, 4 \mathrm{H}), 1.59(\mathrm{tt}, J=7,7 \mathrm{~Hz}, 2 \mathrm{H}), 1.74(\mathrm{tt}, J=7,7 \mathrm{~Hz}, 2 \mathrm{H})$, $3.83(\mathrm{dt}, J=7,7 \mathrm{~Hz}, 2 \mathrm{H}), 4.02$ (t, $J=7 \mathrm{~Hz}, 2 \mathrm{H}), 7.05$ (d, $J=9 \mathrm{~Hz}, 2 \mathrm{H}), 7.69$ (d, $J=9$ $\mathrm{Hz}, 2 \mathrm{H}), 7.83(\mathrm{~d}, J=9 \mathrm{~Hz}, 2 \mathrm{H}), 7.87$ (d, $J=9 \mathrm{~Hz}, 2 \mathrm{H}) ;{ }^{13} \mathrm{C}$ NMR (100 MHz, $\left.\mathrm{DMSO}_{-} \mathrm{d}_{6}\right) \delta=24.9,25.1,28.6,29.9(\mathrm{~d}, J=7 \mathrm{~Hz}), 64.9(\mathrm{~d}, J=5 \mathrm{~Hz}), 67.5,109.1,115.1$, 126.8, 128.3, 130.2, 132.7, 144.3, 159.3; ${ }^{31} \mathrm{P}$ NMR (242.9 MHz, DMSO-d 6 ) $\delta=0.25$; MS m/z (rel intensity) $295\left(\mathrm{M}^{+}-\mathrm{HPO}_{3}, 13\right), 278\left(\mathrm{M}^{+}-\mathrm{H}_{2} \mathrm{PO}_{4}, 3.0\right), 277$ (14), 196 (15), 195 (100). HRMS calcd for $\left[\mathrm{C}_{19} \mathrm{H}_{22} \mathrm{NO}_{5} \mathrm{P}+\mathrm{Na}\right]^{+}$: 398.1128. Found: 398.1127. Elemental anal. calcd for $\mathrm{C}_{19} \mathrm{H}_{22} \mathrm{NO}_{5} \mathrm{P} \cdot \mathrm{CH}_{3} \mathrm{OH}$ : C, 58.96; H, 6.43; N, 3.44\%. Found: $\mathrm{C}$, $58.69 ; \mathrm{H}, 6.32 ; \mathrm{N}, 3.68 \%$. 


\section{Synthesis and Characterization of $\alpha-\mathrm{Fe}_{2} \mathrm{O}_{3}$ Particles}

\section{3-1. Preparation of Monodispersed Spindle-type $\alpha-\mathrm{Fe}_{2} \mathrm{O}_{3}$ Particles $\mathrm{H1}-\mathrm{H3}$ by Seeding Technique}

The spindle-type $\alpha-\mathrm{Fe}_{2} \mathrm{O}_{3}$ fine particles $\mathbf{H 1}-\mathbf{H 3}$, used in the present study, were prepared by the modification of the procedure reported by Ozaki et al. ${ }^{\mathrm{S} 2}$ By using seeding technique, ${ }^{\mathrm{S} 3, \mathrm{~S} 4}$ we could readily controlled particle mean sizes of the spindle-type $\alpha-\mathrm{Fe}_{2} \mathrm{O}_{3}$ particles. Stock solution of $\alpha-\mathrm{Fe}_{2} \mathrm{O}_{3}$ seed particles was prepared by the procedure demonstrated by Sugimoto et $a l .{ }^{\mathrm{S} 3, \mathrm{~S} 4}$ For the reaction, reagent-grade ferric chloride hexahydrate $\left(\mathrm{FeCl}_{3} \bullet 6 \mathrm{H}_{2} \mathrm{O}\right)$ was used as received. The ferric chloride solution was filtered through a $0.2 \mu \mathrm{m}$ Millipore filter to remove any particulate contaminants before use. Following procedure for the preparation of $\mathbf{H 1}$ is the representative one for the size control of $\alpha-\mathrm{Fe}_{2} \mathrm{O}_{3}$.

A 2.0 M ferric chloride aqueous solution $(10.0 \mathrm{~mL}), 6.5 \mathrm{~mL}$ of a stock solution of $\alpha-\mathrm{Fe}_{2} \mathrm{O}_{3}$ seed particles, and a $0.090 \mathrm{M} \mathrm{KH}_{2} \mathrm{PO}_{4}$ solution $(5.0 \mathrm{~mL})$ was added to a $1-\mathrm{L}$ of volumetric flask. After the total volume of the solution was adjusted to $1 \mathrm{~L}$ by the addition of water, the resulting solution was transferred to a 1-L of screw-capped Pyrex bottle and ultrasonicated for $30 \mathrm{~min}$ at room temperature. The resulting solution was aged at $100{ }^{\circ} \mathrm{C}$ for 2 days, and the hot-bottle was immersed in running water. After cooled down to room temperature, the resulting wine red-colored suspension was centrifuged $(8,000 \mathrm{rpm}, 30 \mathrm{~min})$ to obtain solid particles. The resulting solids were washed two times with a $1.0 \mathrm{M} \mathrm{NH}_{3}$ aqueous solution and three times with water, respectively, by dispersing followed by centrifuging (18,000 rpm, $30 \mathrm{~min})$ and finally freeze-dried to obtain $\alpha-\mathrm{Fe}_{2} \mathrm{O}_{3}$ solid particles.

For the preparation of $\mathbf{H 2}$ and $\mathbf{H 3}$, addition amounts of the stock solution of $\alpha-\mathrm{Fe}_{2} \mathrm{O}_{3}$ seed particles were changed to 1.63 and $0.163 \mathrm{~mL}$, respectively. It was necessary to age for $90 \mathrm{~h}$ at $100{ }^{\circ} \mathrm{C}$ to obtain $\mathbf{H 3}$.

\section{3-2. Preparation of Monodispersed Cuboidal $\alpha-\mathrm{Fe}_{2} \mathrm{O}_{3}$ Fine Particle $\mathrm{H} 4$}

Synthesis of $\mathbf{H 4}$ was carried out as the same procedure shown in the literature. ${ }^{\mathrm{S} 3}$ 


\section{3-3. Preparation of Polydispersed Cuboidal $\alpha-\mathrm{Fe}_{2} \mathrm{O}_{3}$ Particle $\mathrm{H5}$}

Initially, monodispersed cuboidal $\alpha-\mathrm{Fe}_{2} \mathrm{O}_{3}$ particles with different in sizes were prepared by the similar way for the preparation of spindle-type particles H1-H3 without addition of phosphate ions. The resulting powders consisting of monodispersed cuboidal particles were mixed together to obtain polydispersed cuboidal particle H5.

\section{3-4. Synthesis of Monodispersed Hexagonal Platelet $\alpha-\mathrm{Fe}_{2} \mathrm{O}_{3}$ Fine Particle $\mathrm{H6}$}

A 500-mL of Pyrex bottle equipped with an efficient mechanical stirrer and immersed in a hot water bath $\left(60{ }^{\circ} \mathrm{C}\right)$ was charged a $2.0 \mathrm{M}$ ferric chloride aqueous solution $(140 \mathrm{~mL})$. Then, a $5.4 \mathrm{M} \mathrm{NaOH}$ aqueous solution $(130 \mathrm{~mL})$ was added dropwise to the stirring solution (300 rpm) over $30 \mathrm{~min}$, and the $\mathrm{pH}$ value of the mixed suspension was adjusted to 1.9 by the further addition of the $\mathrm{NaOH}$ solution. The resulting gel-like suspension in the screw-capped Pyrex bottle was ultrasonicated for 30 min at room temperature. The resulting $\mathrm{Fe}(\mathrm{OH})_{3}$ gel was aged at $100{ }^{\circ} \mathrm{C}$ for $6 \mathrm{~h}$ to convert $\beta-\mathrm{FeOOH}$, and the hot-bottle was cooled down to room temperature by using running water. The resulting brown-colored $\beta$-FeOOH suspension was centrifuged $(18,000 \mathrm{rpm}, 15 \mathrm{~min})$ and washed two times with a $0.5 \mathrm{M} \mathrm{NaNO}_{3}$ aqueous solution by dispersing followed by centrifuging (18,000 rpm, $15 \mathrm{~min})$. Then, the $\beta$-FeOOH solids were re-dispersed in $140 \mathrm{~mL}$ of $\mathrm{H}_{2} \mathrm{O}$ by ultrasonic irradiation to obtain a $\beta-\mathrm{FeOOH}$ stock suspension. The $\beta$-FeOOH stock suspension was transferred in centrifuging tubes (25 mL each, 8 bottles) and centrifuged (18,000 rpm, $15 \mathrm{~min})$. Then, the resulting solid precipitates in the centrifuging tubes were combined and transferred in a $500-\mathrm{mL}$ of screw-capped Pyrex bottle by using an aqueous solution of $7.5 \mathrm{M} \mathrm{NaOH}$ and $2.0 \mathrm{M}$ $\mathrm{NaCl}(400 \mathrm{~mL})$. After ultrasonic irradiation $30 \mathrm{~min}$, the resulting suspension was transferred in 250-mL of screw-capped Teflon bottles (200 mL each, 2 bottles), aged at $70{ }^{\circ} \mathrm{C}$ for 3 days, and cooled down to room temperature. The resulting gel-like materials were centrifuged $(8,000 \mathrm{rpm}, 15 \mathrm{~min})$ and washed with $\mathrm{H}_{2} \mathrm{O}$ by dispersing followed by centrifuging $(8,000 \mathrm{rpm}, 15 \mathrm{~min})$. The resulting solid materials were dispersed in 200 $\mathrm{mL}$ of $1.0 \mathrm{M} \mathrm{HCl}$ and kept at room temperature for 1 day. After centrifuging $(8,000 \mathrm{rpm}$, 
$15 \mathrm{~min}$ ) of the suspension, the red-colored solid precipitates were washed five times with $\mathrm{H}_{2} \mathrm{O}$ by dispersing followed by centrifuging $(5,000 \mathrm{rpm}, 10 \mathrm{~min}$ ) and finally freeze-dried to obtain hexagonal platelet $\alpha-\mathrm{Fe}_{2} \mathrm{O}_{3}$ solid particles $\mathbf{H 6}$.

\section{3-5. Characterization of $\alpha-\mathrm{Fe}_{2} \mathrm{O}_{3}$ Particles H1-H6 by XRD Measurements}

XRD profiles of $\alpha-\mathrm{Fe}_{2} \mathrm{O}_{3}$ fine particles used in the present study are shown in Figure S1. All XRD patterns for the particles H1-H6 were in complete agreement with the JCPDS data for a hematite crystal structure. For comparison, a XRD profile of $\beta$-FeOOH powder, which is intermediate of $\alpha-\mathrm{Fe}_{2} \mathrm{O}_{3}$, is also shown in Figure $\mathrm{S} 1$ (a). As readily seen, even a trace of peak can be assigned as $\beta-\mathrm{FeOOH}$ was not observed in H1-H6. All powders were washed with distilled water, with $1.0 \mathrm{M} \mathrm{NH}_{3}$, again with distilled water repeatedly to completely purify H1-H6 powders before use.

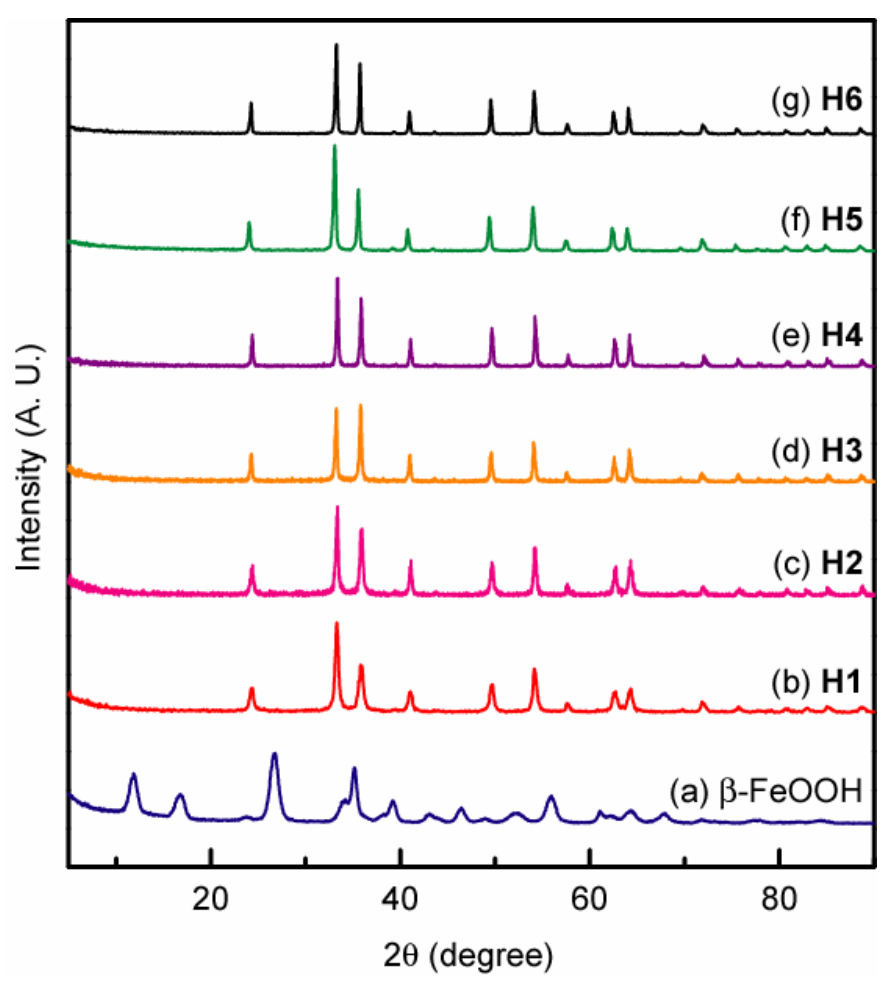

Figure S1. XRD profiles of $\alpha-\mathrm{Fe}_{2} \mathrm{O}_{3}$ particles used in the present study: (a) $\beta-\mathrm{FeOOH}$ powder, (b) H1, (c) H2, (d) H3, (e) H4, (f) H5, and (g) H6. 


\section{3-6. XPS measurements of H1-H6}

The results of XPS measurements on H1-H6 are shown in Figures S2. The spectra are basically identical with each other, showing the characteristics of pure $\alpha-\mathrm{Fe}_{2} \mathrm{O}_{3}$ surfaces.

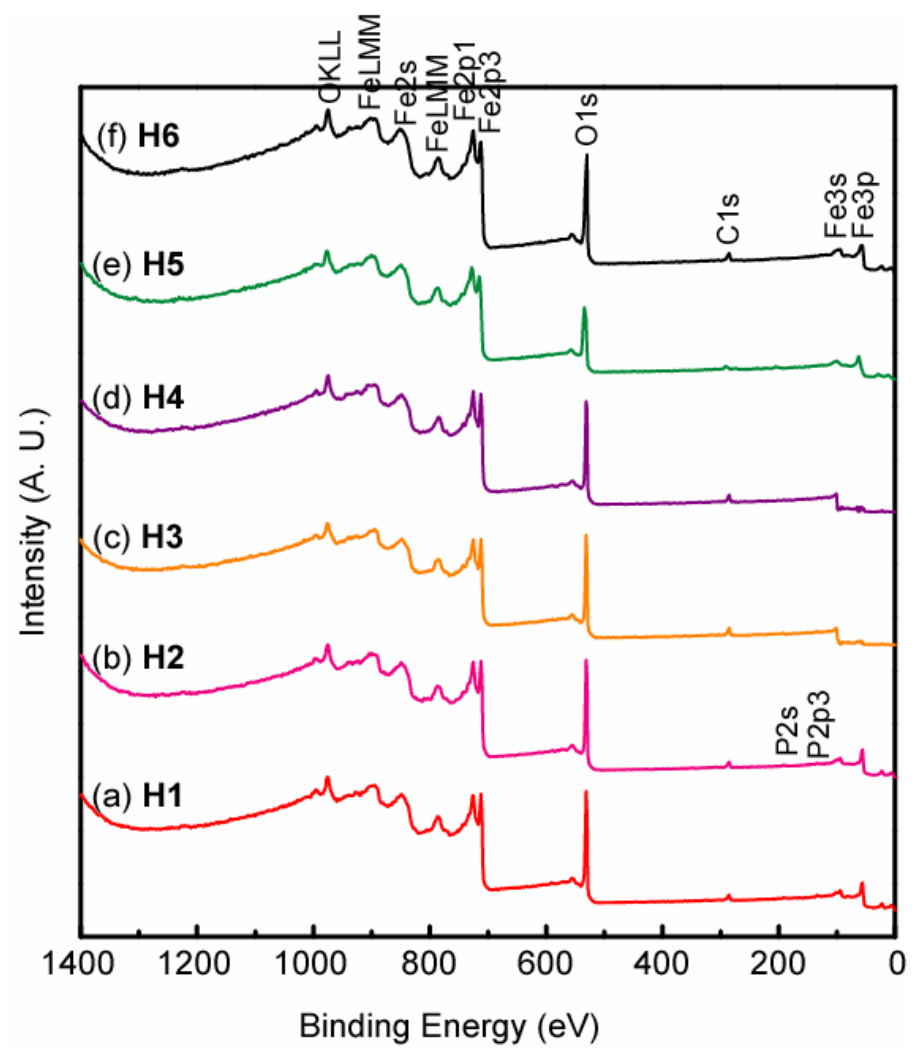

Figure S2. XPS profiles of $\alpha-\mathrm{Fe}_{2} \mathrm{O}_{3}$ particles: (a) H1, (b) H2, (c) H3,

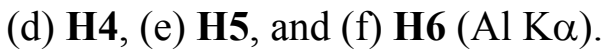

\section{POM Observation of the Hybrid LCs}

\section{4-1. Thermal Behavior of Hybrid L3/H2: Effect of Mesogenic Core}

Thermal behavior of equiponderant hybrid of $\mathbf{L 3} / \mathbf{H 2}=1 / 2$ was examined by the POM observation. Compound $\mathbf{L 3}$ formed an $\mathrm{S}_{\mathrm{A}} \mathrm{LC}$ phase from 57 to $146^{\circ} \mathrm{C}$. However, the liquid crystallinity of $\mathbf{L 3}$ was disappeared by the hybridization and none of mesomorphic behavior for $\mathbf{L 3} / \mathbf{H 2}$ was seen. Only decomposition of $\mathbf{L 3} / \mathbf{H} \mathbf{2}$ was observed at ca. $260{ }^{\circ} \mathrm{C}$. Optical photomicrographs of $\mathbf{L 3} / \mathbf{H 2}=1 / 2$ at $110{ }^{\circ} \mathrm{C}$ with and without a polarizer are shown in Figure S3. 


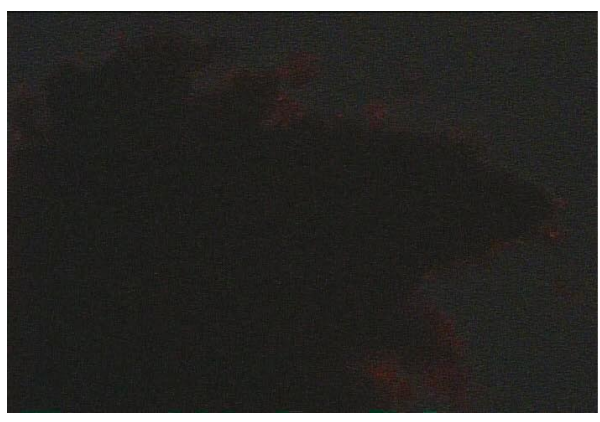

(a) with a polarizer

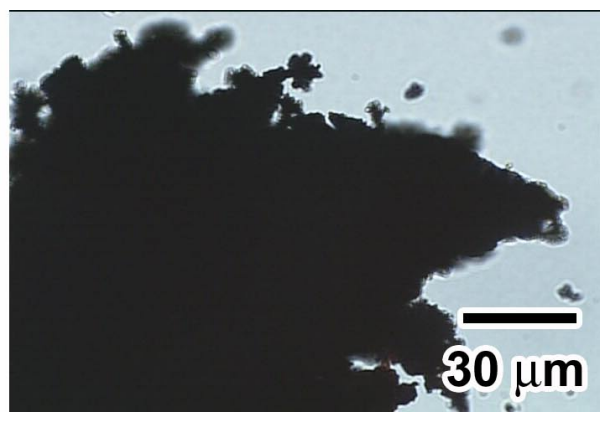

(b) without a polarizer

Figure S3. Optical photomicrographs of $\mathbf{L 3} / \mathbf{H 2}=1 / 2$ at $110{ }^{\circ} \mathrm{C}$.

\section{Temperature variable SAXS Measurements of the Hybrid LCs}

Figure S4 shows the SAXS profiles of the $\mathbf{L 1} / \mathbf{H} 2=1 / 2$ hybrid at 90 and $170{ }^{\circ} \mathrm{C}$ and the $\mathbf{H} 2$ powder. The scattering profiles suggested the existence of periodic particle interactions at intervals of 49.7 and $46.5 \mathrm{~nm}$ at 90 and $170{ }^{\circ} \mathrm{C}$, respectively, for the $\mathbf{L 1} / \mathbf{H} \mathbf{2}=1 / 2$ hybrid. Such periodic structure was not observed for the $\mathbf{H} \mathbf{2}$ powder.

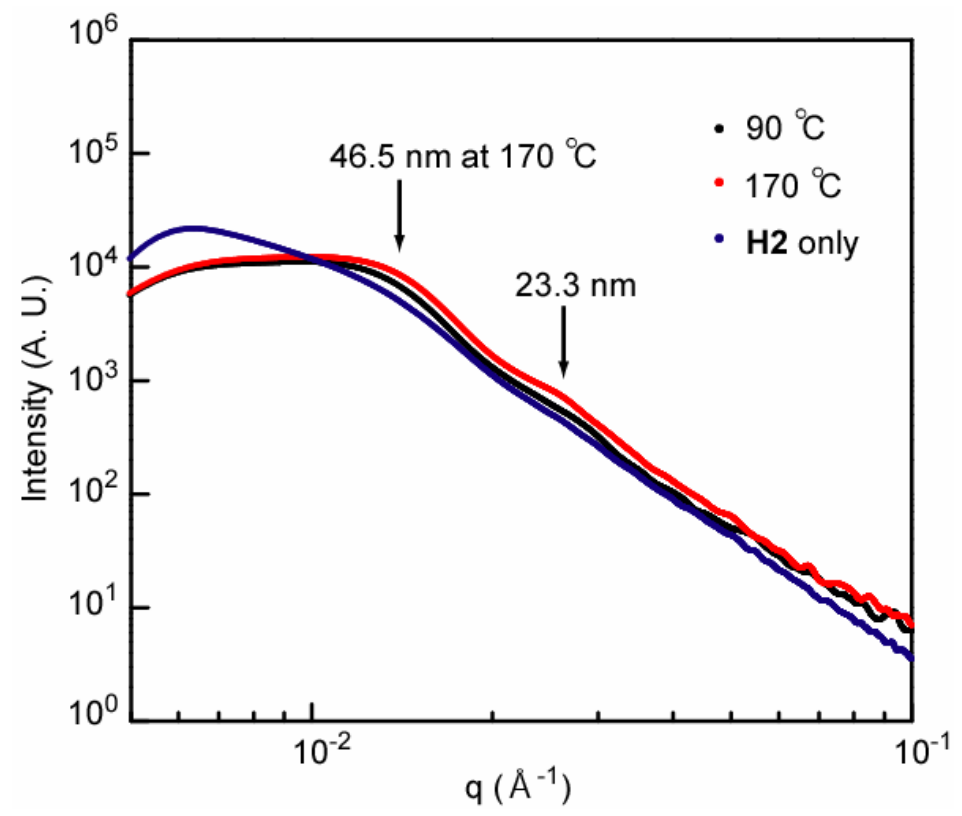

Figure S4. SAXS profiles of the $\mathbf{L 1} / \mathbf{H} 2=1 / 2$ hybrid at 90 and $170{ }^{\circ} \mathrm{C}$ as well as the $\mathbf{H} \mathbf{2}$ powder. 
The results of SAXS measurements for the hybrid of $\mathbf{L 1} / \mathbf{H} \mathbf{4}=1 / 1$ as well as the $\mathbf{H 4}$ powder are summarized in Figure S5. For the hybrid of L1/H4 $=1 / 1$, scatterings of $45.6,30.4$, and $22.8 \mathrm{~nm}$ at $170^{\circ} \mathrm{C}$ are corresponding to $\mathrm{d}_{200}, \mathrm{~d}_{300}$, and $\mathrm{d}_{400}$ planes of a superlattice structure with a simple cubic LC structure. The lattice parameter can be assigned as $a=91.2 \mathrm{~nm}$. The superlattice structures are only observed after the hybridization of $\mathbf{L} \mathbf{1}$ and $\mathbf{H} \mathbf{4}$.

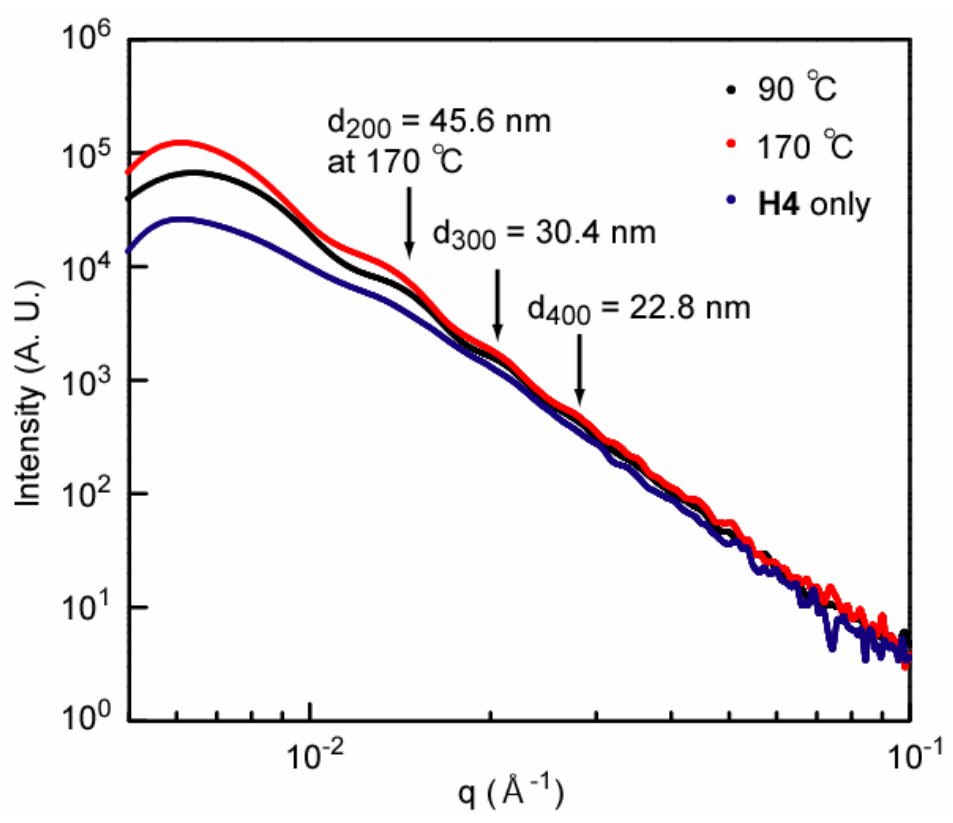

Figure S5. SAXS profiles of the $\mathbf{L 1} / \mathbf{H} 4=1 / 1$ hybrid at 90 and $170{ }^{\circ} \mathrm{C}$ as well as the $\mathbf{H} \mathbf{4}$ powder.

On the other hand, SAXS patterns of the $\mathbf{L 1} / \mathbf{H 5}=1 / 2$ hybrid at 90 and $170{ }^{\circ} \mathrm{C}$ and the $\mathbf{H 5}$ powder are shown in Figure S6. None of peaks due to the periodic interparticle interaction by the formation of liquid crystalline order were observed before and after hybridization. 


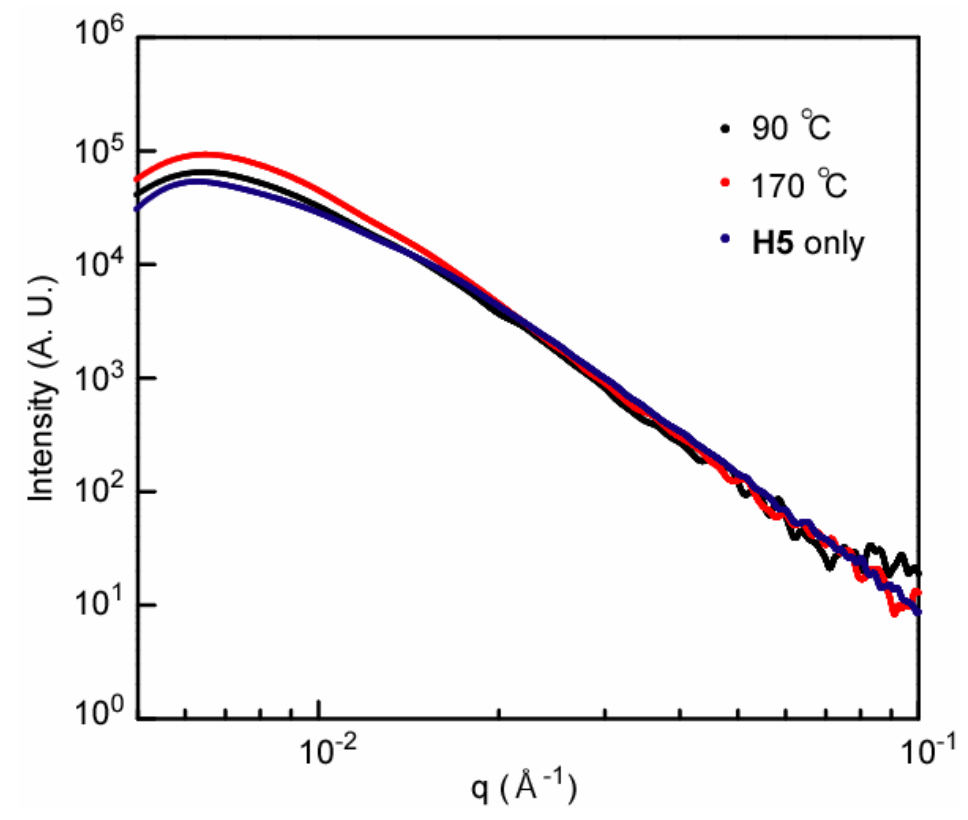

Figure S6. SAXS profiles of the $\mathbf{L 1} / \mathbf{H 5}=1 / 2$ hybrid at 90 and $170{ }^{\circ} \mathrm{C}$ as well as the $\mathbf{H 5}$ powder.

\section{Temperature-variable FT-IR Measurements of the Hybrid LCs}

Figure S7 exhibits the results of temperature-variable FT-IR measurements of H2, H6, L1, L1/H2, and L1/H6. For the L1 single component, two bands corresponding to $\mathrm{PO}-\mathrm{H}$ stretching and $\mathrm{POH}$ combination vibration appear at 2690 and $2300 \mathrm{~cm}^{-1}$, respectively. Similar absorption bands are also seen for the mixture of L1/H6 $=1 / 2$ at the same temperatures, which can be attributable to the existence of phase segregated free component of L1. On the other hand, such absorption bands are entirely disappeared by the hybridization of $\mathbf{L 1}$ and $\mathbf{H 2}$ (Figure S7 (e) and (f)). These results mean that most of all the $\mathbf{L} 1$ molecules are densely adsorbed on the $\mathbf{H} \mathbf{2}$ surfaces by the specific adsorption of the $\mathrm{PO}_{3} \mathrm{H}_{2}$ moiety of $\mathbf{L 1}$, and no free $\mathbf{L 1}$ molecules are present in the hybrid. 


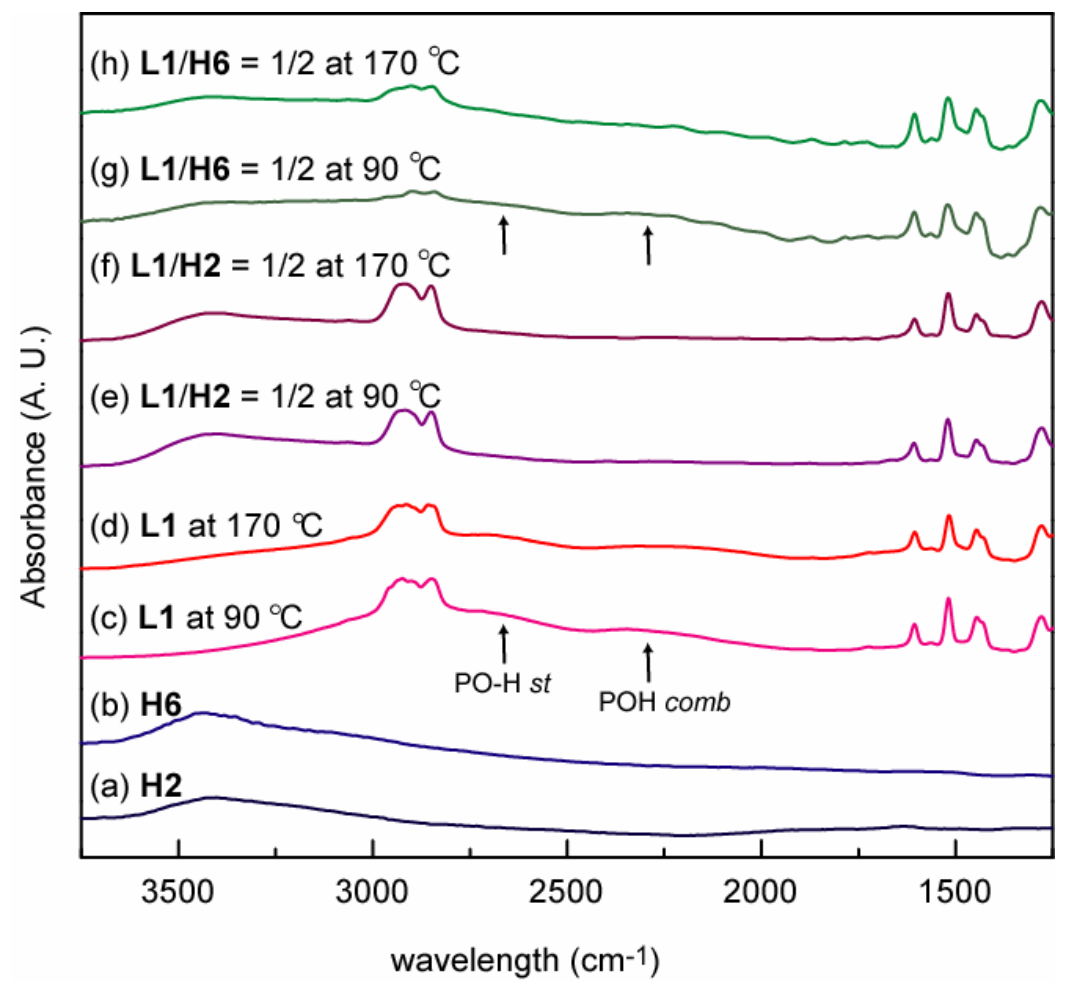

Figure S7. Temperature-variable FT-IR spectra of (a) H2, (b) H6, (c) L1 at $90{ }^{\circ} \mathrm{C}$, (d) $\mathbf{L} 1$ at $170{ }^{\circ} \mathrm{C}$, (e) $\mathbf{L 1} / \mathbf{H 2}=1 / 2$ at $90{ }^{\circ} \mathrm{C}$, (f) $\mathbf{L 1} / \mathbf{H 2}=1 / 2$ at $170{ }^{\circ} \mathrm{C}$, (g) $\mathbf{L 1} / \mathbf{H 6}=1 / 2$ at $90{ }^{\circ} \mathrm{C}$, (h) $\mathbf{L 1} / \mathbf{H 6}=1 / 2$ at $170{ }^{\circ} \mathrm{C}$.

\section{References for Supporting Information}

(S1) Kanie, K.; Takehara, S.; Hiyama, T. Bull. Chem. Soc. Jpn., (2000), 73, 1875.

(S2) Lindberg, J.; Ekeroth, J.; Konradsson, P. J. Org. Chem., (2002), 67, 194.

(S3) Sugimoto, T.; Wang, Y.; Itoh, H.; Muramatsu, A. Colloids Surf. A (1998), 134, 265.

(S4) Sugimoto, T.; Muramatsu, A. J. Colloid Interface Sci. (1996), 184, 626. 